\title{
INVERSIÓN Y DERECHO INTERNACIONAL DE LA INVERSIÓN EXTRANJERA. REFLEXIÓN SOBRE ALGUNAS DISCIPLINAS ADOPTADAS POR MÉXICO
}

\author{
Sergio LÓPEZ-AYLLÓN* \\ Alejandro POSADAS URTUSUÁSTEGUI**
}

RESUMEN: En el presente artículo se plantea un análisis del régimen de derecho internacional de la inversión extranjera en el marco de los procesos de integración económica de México, así como del panorama de la inversión extranjera en el mundo y cómo en ella se inserta México. Bajo este contexto se analizan tres instituciones jurídicas que México ha adoptado por medio de una serie de tratados internacionales relacionados con el clima de inversión productiva, dichas instituciones son: el criterio de nivel mínimo de trato a los inversionistas extranjeros bajo el derecho internacional, la disciplina de libre transferencia y convertibilidad y, por último, las exenciones impositivas a organismos internacionales financieros con personalidad jurídica.

ABSTRACT: In this Article, the authors analyze the foreign investment law regime in Mexico in the context of the economic integration processes Mexico has undertaken, and in the context of foreign investment flows worldwide. In particular the Article addresses three legal disciplines that Mexico has adopted through a number of international agreements, namely, the foreign investment minimum treatment standard, the discipline of free transfers and movement of capitals, and the tax treatment to foreign persons and international organizations.

RÉSUMÉ: Cet article est un analyse du régime du droit internationale de l'investissement étrangère aux processus d'integration economique à Mexique, du panorama de l'investissement étrangère dans le monde, et de la forme dans laquelle s'inserte à Mexique. Dans ce contexte, trois institutions juridiques sont analysées même que le Mexique a adopté a travers de plusieurs traités internationaux sur l'investissement productif. Cettes institutions sont: le critère de minimum niveau de traitement aux investisseurs étrangères sous le droit internationale, la discipline de livre transférence et convertibilité, et en dernier lieu, les exonerations fiscales aux organismes financières internationales avec personalité legale.

* Profesor investigador de la División de Administración Pública del CIDE. Doctor en derecho por la Universidad Nacional Autónoma de México.

** Profesor investigador y director de la División de Estudios Jurídicos del CIDE. Doctor en derecho por la Universidad de Duke (EUA). Los autores desean agradecer la valiosa colaboración de Carlos González, asistente de la División de Estudios Jurídicos del CIDE, en la elaboración del artículo. Sin embargo, las opiniones y errores son responsabilidad exclusiva de los mismos. 
SUMARIO: I. Introducción. II. La inversión en el contexto de los procesos de integración económica de México. III. México y el derecho internacional de la inversión extranjera. IV. Conclusión y comentarios finales. V. Bibliografia.

\section{INTRODUCCIÓN}

La inversión extranjera en México ha tenido un crecimiento importante desde la década de los noventa en gran medida como resultado de la decisión del Estado mexicano de adoptar una serie de políticas estructurales de apertura comercial, integración económica con otras regiones del mundo y políticas de estabilidad macroeconómica. Adicionalmente se han dado pasos relevantes que inciden en el clima o ambiente favorable para la inversión productiva, tanto extranjera como nacional, tales como el desarrollo de una política de competencia, de desregulación y más recientemente en materia de transparencia y acceso a la información, entre otras. Como parte de los procesos de integración económica en los que se ha insertado activamente México desde finales de los ochenta se encuentra la adopción de ciertas disciplinas y obligaciones en materia de trato a la inversión extranjera. Así la política de México en este sentido ha sido adoptar procesos de integración comercial y de inversión conjuntamente. Desde el punto de vista jurídico, a través de un número importante de tratados internacionales, México ha incorporado a su sistema jurídico tanto obligaciones, criterios y estándares de trato a la inversión extranjera, como mecanismos para resolver conflictos que se deriven de estas obligaciones. Uno de los aspectos menos analizados de los procesos de integración ha sido el del análisis puntual de las disciplinas y criterios de trato a la inversión extranjera y de su relación con el clima de la inversión productiva como política gubernamental. El objetivo central de este artículo es hacer un análisis de algunas de estas disciplinas y esbozar unas primeras reflexiones sobre su utilidad como modelos para ampliar el ámbito de las políticas que procuren un mejor ambiente para la inversión productiva y el desarrollo económico.

En este artículo partimos en la sección II de un análisis de los procesos de integración económica de México, del papel de los acuerdos en materia de inversión dentro de estos procesos, así como de la revisión sumaria de la situación de la inversión extranjera en el mundo y en México. En la tercera sección hacemos el análisis de ciertas obligaciones interna- 
cionales relevantes en materia de inversión extranjera. En particular analizamos el criterio o estándar mínimo de trato, las obligaciones de libre convertibilidad y transferencia, así como las posibilidades de exención al régimen fiscal de los extranjeros. El análisis de estos aspectos concluye con una reflexión inicial en la sección IV sobre la viabilidad de diseñar políticas de fortalecimiento del régimen y clima de la inversión a nivel nacional. Utilizamos así esas instituciones jurídicas internacionales para generar una primera reflexión sobre el tipo de reglas, instituciones y procesos que pudieran fortalecer el régimen nacional aplicable a los capitales productivos.

\section{LA INVERSIÓN EN EL CONTEXTO DE LOS PROCESOS DE INTEGRACIÓN ECONÓMICA DE MÉXICO}

\section{Procesos de integración económica}

Desde la década de los ochenta, México inició un proceso de transformación sustantiva de su modelo de desarrollo económico. En una síntesis muy apretada, se abandonó - por agotamiento- el modelo de economía cerrada basada en la sustitución de importaciones, ${ }^{1}$ para iniciar el proceso de apertura de mercados, liberalización, desregulación y control del déficit público. ${ }^{2}$ Conforme esta lógica se redujeron las barreras al comercio (aranceles y otras medidas no arancelarias), se adoptaron tasas de cambio flexibles, se modificó la legislación en materia de inversión extranjera, se eliminaron las restricciones a los flujos de capital, se privatizaron algunas empresas públicas y se privilegió el equilibrio macroeconómico como premisa para el crecimiento. ${ }^{3}$ Estas medidas fueron diseñadas en gran medida para responder a los problemas que enfrentaba la región. El Premio Nobel de Economía, Joseph Stiglitz, ha escrito al respecto:

1 En este modelo tuvo un papel muy significativo las concepciones de la CEPAL. Conforme a la teoría del economista Raúl Prebisch era "necesario fortalecer el sector industrial con mecanismos de protección mientras se creaba una estructura productiva fortalecida para competir a nivel latinoamericano, en mercados que se abrirían por medio de la integración y posteriormente en mercados internacionales" citado por Vega Cánovas, (1987, 66 )

2 Véase, entre otros, Bazdresch, Bucal et al. 1992; Aspe Armella, 1993.

3 Para un análisis de los cambios jurídicos véase, entre otros, Valdez Abascal y Romero Apis, 1994; López Ayllón, 1997; Cossío Díaz, 2001. 
En los años ochenta los gobiernos de dichos países [América Latina] habían tenido a menudo grandes déficits. Las pérdidas en las ineficientes empresas públicas contribuyeron a dichos déficits. Aisladas de la competencia gracias a medidas proteccionistas, las empresas privadas ineficientes forzaron a los consumidores a pagar precios elevados. La política monetaria laxa hizo que la inflación se descontrolara. Los países no pueden mantener déficits abultados y el crecimiento sostenido no es posible con hiperinflación. ${ }^{4}$

Es importante destacar que este proceso de cambio no fue exclusivo de México, sino que se inscribió dentro de corrientes mayores de transformación relacionadas con la "globalización" de la economía y una reorientación del papel del Estado que fue común, con matices propios en cada país, a la región de América Latina y en general, a otras regiones del mundo como el sureste asiático y Europa oriental. 5 De este modo, junto con el cambio económico se configuró una transición hacia un Estado latinoamericano bajo los paradigmas globales de democracia, mercado y Estado de derecho. ${ }^{6}$

Una de las consecuencias más importantes del cambio de modelo económico lo constituyó el proceso de integración al sistema económico internacional y, en particular, al del continente americano. En este proceso México determinó jugar un papel muy activo que buscaba aprovechar al máximo sus ventajas competitivas y desarrollar una estrategia que lo posicionara como un lugar atractivo para la inversión y el comercio internacional.

Esta estrategia, que se inicia desde finales de los noventas y se prolonga hasta los primeros años del siglo XXI, tiene varios planos de desarrollo. ${ }^{7}$ El primero se ubica en el ámbito multilateral, y se concreta en el ingreso de México en el entonces GATT, ${ }^{8}$ y posteriormente en un papel activo durante las negociaciones finales de la Ronda Uruguay que condujeron a la creación de la Organización Mundial del Comercio y la generación de un auténtico sistema multilateral de comercio. ${ }^{9}$ También en el

\footnotetext{
Stiglitz 2002, 81

Véase, entre otros, Baer y Bircj, 1992; Grindle, 1996; Kaplan, 1996.

Véase Greenberg, 1993; Haggard y Kaufman, 1995; Przeworsky 1995; Linz y Stepan, 1996.

Véase Blanco Mendoza, 1994.

Véase Torres, 1991.

9 Sobre el sistema multilateral de comercio véase, entre otros, Jackson, 1999; Witker y Hernández, 2000; OMC, 2003.
} 
plano multilateral México buscó y obtuvo su ingreso a la Organización de Cooperación y Desarrollo Económico (OCDE) y participa de manera activa en otros organismos económicos multilaterales.

Desde el punto de vista regional, un punto de inflexión de enorme importancia lo constituyó la negociación y firma del Tratado de Libre Comercio de América del Norte con los Estados Unidos de América y Canadá (en adelante TLCAN). Este instrumento, aprobado por el Senado de la República en 1992, implicó no sólo el acceso preferencial al mercado de los Estados Unidos, históricamente el socio comercial más importante del país, sino también la inclusión integral, por primera vez en un tratado comercial, de disciplinas en materia de inversión. En otras palabras, el TLCAN es, a la vez, un tratado de libre comercio e inversión ${ }^{10}$ que aseguraba a nuestro país un acceso a las fuentes de inversión necesarias para soportar el crecimiento económico que se esperaba lograr.

El modelo del TLCAN fue utilizado posteriormente en la estrategia complementaria del país que, conforme al marco regional contenido en la Asociación Latinoamericana de Integración (ALADI), inició negociaciones con diversos países de la región para completar nuevos tratados de libre comercio e inversión. A la fecha México, ha completado siete tratados de libre comercio e inversión: uno con Guatemala, Honduras y El Salvador, ${ }^{11}$ uno con Nicaragua, ${ }^{12}$ uno con Costa Rica, ${ }^{13}$ uno con Chile, ${ }^{14}$ uno con Colombia y Venezuela, ${ }^{15}$ uno con Bolivia ${ }^{16}$ y uno con Urut guay, ${ }^{17}$ así como tres tratados bilaterales en materia de inversión con

10 Véase López Ayllón, 1997; Von Wobeser, 2000.

11 Tratado de Libre Comercio entre los Estados Unidos Mexicanos y las repúblicas de El Salvador, Guatemala y Honduras. Publicado en el Diario Oficial de la Federación (en adelante DOF) el 14 de marzo y 30 de mayo de 2001.

12 Tratado de Libre Comercio entre el Gobierno de los Estados Unidos Mexicanos y el Gobierno de la República de Nicaragua. Publicado en el $D O F$ el 1 de julio de 1998.

13 Tratado de Libre Comercio entre los Estados Unidos Mexicanos y la República de Costa Rica. Publicado en el $D O F$ el 10 de enero de 1995.

14 Tratado de Libre Comercio entre la República de Chile y los Estados Unidos Mexicanos. Publicado en el DOF el 28 de julio de 1999.

15 Tratado de Libre Comercio entre los Estados Unidos Mexicanos, la República de Colombia y la República de Venezuela. Publicado en el DOF el 9 de enero de 1995.

16 Tratado de Libre Comercio entre los Estados Unidos Mexicanos y la República de Bolivia. Publicado en el $D O F$ el 11 de enero de 1995.

17 Tratado de Libre Comercio entre los Estados Unidos Mexicano y la República Oriental del Uruguay. Publicado en el DOF el 14 de julio de 2004. 
Uruguay, Argentina y Cuba. ${ }^{18}$ Todos estos tratados han sido, en su momento, aprobados por el Senado de la República. Simultáneamente, México ha participado activamente en otros foros de negociación regionales, especialmente aquellos relacionados con la negociación, aún inconclusa, del Acuerdo de Libre Comercio de las Américas (ALCA) ${ }^{19}$ y más recientemente ha incursionado en el Mercosur, foro en el cual fue recientemente admitido con el estatus de Estado asociado.

Más allá del marco regional, México buscó ampliar sus ventajas comparativas mediante una estrategia que permitiera estabilizar sus relaciones comerciales con otras regiones del mundo. Bajo esta óptica México ha participado en el Mecanismo de Cooperación Económica Asia-Pacífico (APEC) desde 1993, cuyo propósito es la creación, mediante el concepto del regionalismo abierto, un área de libre comercio para el 2020. Recientemente México concluyó la negociación de un Tratado de Libre Comercio con Japón, mismo que entró en vigor el 1o. de abril del 2005. México es el segundo país con el que Japón firma un tratado de esta naturaleza y con ello se abren oportunidades únicas para que los productos mexicanos ingresen en ese atractivo mercado. Anteriormente México

18 La lista de Tratados Bilaterales de Promoción y Protección Recíproca de las Inversiones (APRIs) celebrados por México, se compone de los siguientes: Acuerdo entre los Estados Unidos Mexicanos y la República de Cuba para la Promoción y Protección Recíproca de las Inversiones (DOF 3 de mayo de 2002); Acuerdo entre el Gobierno de los Estados Unidos Mexicanos y el Gobierno de la República Argentina para la Promoción y Protección Recíproca de las Inversiones (DOF 20 de agosto de 1998); Acuerdo entre los Estados Unidos Mexicanos y la Confederación Suiza para la Promoción y Protección Recíproca de las Inversiones (DOF 20 de agosto de 1998); Acuerdo entre el Gobierno de los Estados Unidos Mexicanos y el Gobierno del Reino de Dinamarca para la Promoción y Protección Recíproca de las Inversiones (DOF 30 de noviembre de 2000); Acuerdo entre el Gobierno de los Estados Unidos Mexicanos y el Gobierno de la República Francesa para la Promoción y Protección Recíprocas de Inversiones (DOF 30 de noviembre de 2000); Acuerdo Para la Promoción y Protección Recíproca de las Inversiones entre los Estados Unidos Mexicanos y El Reino de los Países Bajos (DOF 10 de julio de 2000); Acuerdo entre los Estados Unidos Mexicanos y la República de Austria sobre la Promoción y Protección de las Inversiones (DOF 23 de marzo de 2001); Acuerdo entre los Estados Unidos Mexicanos y la República Federal de Alemania sobre Promoción y Protección Recíproca de las Inversiones (DOF 20 de marzo de 2001); Acuerdo sobre la Promoción y Protección Recíproca de las Inversiones entre los Estados Unidos Mexicanos y la República Portuguesa (DOF 8 de enero de 2001); Acuerdo entre el Gobierno de los Estados Unidos Mexicanos y el Gobierno de la República de Finlandia para la Promoción y Protección Recíproca de Inversiones (DOF 30 de noviembre de 2000); Acuerdo entre el Gobierno de los Estados Unidos Mexicanos y el Gobierno del Reino de Suecia para la Promoción y Protección Recíproca de las Inversiones (DOF 27 de julio de 2001); Acuerdo entre los Estados Unidos Mexicanos y el Gobierno del Reino de España para la Promoción y Protección Recíproca de Inversiones (DOF 19 de marzo de 1997).

19 Para una amplia información sobre este proceso véase la página electrónica www.ftaa-alca.org 
concluyó un tratado de libre comercio con Israel, el cual se encuentra en vigor desde el 1o. de julio del 2000, y uno con la Asociación Europea de Libre Comercio (Islandia, Noruega, Liechtenstein y Suiza), en vigor desde el 1o. de julio del 2001.

Uno de los esfuerzos más importantes de México para diversificar el comercio y la inversión mediante un proceso de integración económica lo constituyó las negociaciones con la Unión Europea que, luego de un largo y complejo proceso, concluyeron con la firma del Acuerdo de Asociación Económica, Concertación Política y Cooperación entre los Estados Unidos Mexicanos y la Comunidad Europea y sus Estados Miembros (en adelante el Acuerdo de Asociación, aprobado por el Senado de la República el 20 de marzo de 2000), y posteriormente de dos decisiones del Consejo Conjunto que contienen las reglas específicas en materia de liberalización comercial, así como las disciplinas convenidas en materia de movimiento de capital y propiedad intelectual y que en conjunto constituyen lo que se conoce como el Acuerdo de Libre Comercio entre México y la Unión Europea. ${ }^{20}$

Debido a la peculiar estructura jurídica de la Unión Europea, ${ }^{21}$ la política comercial en materia de comercio de bienes y los aspectos que inciden en ellos (por ejemplo subsidios y normas técnicas) son competencia exclusiva de la Unión. En cambio, los aspectos relacionados con el comercio de servicios, la inversión y la propiedad intelectual son competencia común entre la Unión y sus Estados miembros. Por ello, en el texto del Acuerdo de Asociación, las disposiciones relacionadas con la inversión se limitan a una serie de compromisos genéricos para establecer condiciones atractivas y estables para las inversiones recíprocas, en particular mecanismos de información; apoyos al desarrollo de un entorno jurídico favorable a la inversión (particularmente mediante la firma entre México y los Estados miembros de la Unión de acuerdos recíprocos de promoción y protección a la inversión y de acuerdos destinados a evitar la doble imposición); desarrollo de procedimientos administrativos simplificados y armonizados; y el desarrollo de mecanismos de inversión conjunta (véase artículo 15 del Acuerdo de Asociación). Asimismo, destaca el compromiso de México y la Unión Europea, establecido en el 
artículo 44.2 del Acuerdo de Asociación, de instar al Banco Europeo de Inversiones a "continuar sus actividades en México".

Por su parte, los artículos 28 a 35 de la Decisión 2/2001 del Consejo Conjunto desarrollan obligaciones específicas en materia de liberalización de pagos relacionados con inversión; dificultades por políticas cambiarias y monetarias; dificultades en la balanza de pagos; transferencias, fomento a las inversiones y confirmación de los compromisos internacionales en materia de inversión, especialmente los Códigos de Liberalización y el Instrumento de Trato Nacional de la OCDE.

Ahora bien, en materia de inversiones y por la razón ya explicada, junto con las disposiciones generales del Acuerdo de Asociación y la Decisión 2/2001 del Consejo Conjunto, México ha celebrado 13 acuerdos bilaterales en materia de promoción y protección de la inversión extranjera (APRI) ${ }^{22}$ con diversos países miembros de la Unión (Alemania, Países Bajos, Austria, España, Unión Belgo-Luxemburguesa, Francia, Finlandia, Portugal, Italia, Dinamarca, Grecia, Suecia y República Checa) ${ }^{23}$ De este modo, y a diferencia del TLCAN que consolida en un instrumento único las disciplinas en materia de comercio e inversión, la regulación jurídica en materia de fomento y protección a la inversión con los países de la Unión Europea se regulan tanto por el Acuerdo de Asociación como por los APRI. Adicionalmente México ha celebrado un Apri con Suiza y otro con Corea del Sur en Asia. Recientemente se concluyeron negociaciones con Australia e Islandia, y se conducen con Gran Bretaña e Israel.

\section{La inversión extranjera directa}

La mayor parte de los flujos de inversión extranjera directa (en adelante IED) en el mundo se originan en los países con economías muy desarrolladas, y contra lo que pudiera pensarse, se dirigen generalmente ha-

22 Los APRI son tratados internacionales en materia de inversión extranjera directa que, sobre las bases de reciprocidad, son diseñados para el fomento y la protección jurídica de los flujos de capital destinados al sector productivo. Estos instrumentos se reconocen como un elemento generador de confianza para los inversionistas extranjeros, ya que permiten el establecimiento de un clima favorable a la inversión. Actualmente existen más de 2100 APRI firmados en el mundo. Típicamente un Apri contiene disciplinas en materia de definición de Inversión, promoción y admisión de inversiones, ámbito de aplicación, trato de las inversiones, expropiación, transferencias, solución de controversias inversionista —Estado y Estado- Estado y disposiciones finales. Véase Khalil, 1992.

23 Todos estos APRI han sido aprobados por el Senado de la República. Para una lista completa de los APRI firmados por México véase supra nota 18. 
cia esos mismos países, entre los que podemos destacar a Estados Unidos de América, Reino Unido, Japón, Alemania, Francia, Holanda y Canadá. ${ }^{24}$ En las últimas dos décadas, el crecimiento agregado de la IED ha sido extraordinariamente rápido, pero su distribución geográfica muy desigual. Básicamente 10 países contribuyen con la mayor parte de los flujos de IED en el mundo. Sin embargo, su participación agregada ha disminuido del $93 \%$ en 1960 a sólo $74 \%$ en 2000, en beneficio de otros países, en su mayoría desarrollados, pero también de nuevos actores, principalmente los países del sureste asiático, en especial Hong Kong, Singapur, Taiwán y China. Sólo un país latinoamericano, Brasil, ocupa en lugar significativo como exportador de flujos de IED. La tabla 1 (véase la siguiente página) sintetiza el estado de los flujos de IED en el mundo.

En cuanto al destino de la IED, ésta se concentra también en los países desarrollados. Datos de la UNCTAD estiman que en 2000 sólo el $33 \%$ de los flujos de IED tenían como destino a los países en desarro1lo. ${ }^{25}$ De ese porcentaje, $70.4 \%$ se concentraba en diez países, de los cuales sólo 3 eran latinoamericanos (Brasil 10\%, México 4.6 y Argentina el $3.7 \%$ ). Es particularmente importante hacer notar el crecimiento espectacular del porcentaje de IED recibida por los países de Asia, que creció del $21 \%$ en 1975 a $64 \%$ en 2000 (China recibió por sí sola el 17.5\%). Así, ante la creciente demanda de capital y la escasez relativa en el sistema internacional, asistimos a una intensa competencia entre países en desarrollo por atraer los flujos de IED. La tabla 2 (véase en página posterior) muestra esta situación.

La importancia relativa de la IED en la economía de los países receptores varía de uno a otro. Una manera de medirla es compararla con el PIB del país en cuestión. Una tendencia general en todos los países es el incremento significativo de su importancia relativa en las economías nacionales. La tabla 3 (véase en página próxima) muestra claramente esta situación. En el caso particular de México, para 1999 la IED representó el $16.4 \%$ del PIB.

25 Esta situación contrasta con la que existía antes de la II Guerra Mundial en la que el $65 \%$ de la IED se localizaba en países en desarrollo (Dicken 2003, 58). 
Tabla 1. Porcentaje del total mundial de flujos de salida de IED

\begin{tabular}{|c|c|c|c|c|c|c|}
\hline País & 1960 & 1975 & 1985 & 1990 & 1995 & 2000 \\
\hline EUA & 47.1 & 44.0 & 35.5 & 25.1 & 24.3 & 20.8 \\
\hline Reino Unido & 18.3 & 13.1 & 14.2 & 13.4 & 10.6 & 15.1 \\
\hline Japón & 0.7 & 5.7 & 6.2 & 11.7 & 8.3 & 4.7 \\
\hline Alemania & 1.2 & 6.5 & 8.5 & 8.6 & 9.0 & 7.4 \\
\hline Francia & 6.1 & 3.8 & 5.2 & 7.0 & 7.2 & 8.3 \\
\hline Holanda & 10.3 & 7.1 & 6.8 & 6.0 & 5.8 & 5.5 \\
\hline Canadá & 3.7 & 3.7 & 6.1 & 4.9 & 4.1 & 3.4 \\
\hline Suiza & 3.4 & 8.0 & 3.5 & 3.9 & 4.9 & 3.9 \\
\hline Italia & 1.6 & 1.2 & 2.4 & 3.3 & 3.8 & 3.0 \\
\hline Suecia & 0.6 & 1.7 & 1.5 & 2.9 & 2.5 & 1.9 \\
\hline Total & 93.0 & 94.8 & 89.9 & 86.8 & 80.5 & 74.0 \\
\hline
\end{tabular}


Tabla 2. Concentración de la IED en países en desarrollo, 2000

\begin{tabular}{|l|r|r|}
\hline \multicolumn{1}{|c|}{ País } & $\begin{array}{r}\text { Inversión extranjera directa (millones } \\
\text { de dólares) }\end{array}$ & \% del total de países en desarrollo \\
\hline Hong Kong & 369,776 & 23.7 \\
\hline China & 346,694 & 17.5 \\
\hline Brasil & 197,652 & 10.0 \\
\hline México & $\mathbf{9 1 , 2 2 2}$ & $\mathbf{4 . 6}$ \\
\hline Singapur & 89,250 & 4.5 \\
\hline Argentina & 73,441 & 3.7 \\
\hline Indonesia & 60,638 & 2.9 \\
\hline Malasia & 54,315 & 2.7 \\
\hline Chile & 42,933 & 2.2 \\
\hline Corea del Sur & 42,329 & 2.1 \\
\hline Total & $1,056,220$ & 70.4 \\
\hline
\end{tabular}


Tabla 3. Porcentaje de la IED en el PIB en países seleccionados

\begin{tabular}{|l|r|r|}
\hline \multicolumn{1}{|c|}{ País } & 1990 & 1999 \\
\hline Países desarrollados (promedio) & 8.4 & 14.5 \\
\hline País en desarrollo (promedio) & 13.4 & 28.0 \\
\hline Singapur & 76.3 & 97.5 \\
\hline Malasia & 24.1 & 65.3 \\
\hline Chile & 33.2 & 55.2 \\
\hline China & 7.0 & 30.0 \\
\hline Argentina & 6.4 & 22.2 \\
\hline Brasil & 8.0 & 21.6 \\
\hline Pakistán & 4.8 & 17.2 \\
\hline México & $\mathbf{8 . 5}$ & $\mathbf{1 6 . 4}$ \\
\hline India & 0.6 & 3.6 \\
\hline
\end{tabular}




\section{Inversión extranjera directa en México}

La inversión extranjera directa en México ha crecido de manera significativa desde 1985, luego del inicio de los cambios estructurales y la firma de acuerdos comerciales de integración. A partir de la decisión del Estado mexicano de abandonar la política de sustitución de importaciones por una de apertura comercial y financiera, la inversión extranjera directa recibió un fuerte impulso. Este incentivo se reforzó aún más con la entrada en vigor del TLCAN y otros instrumentos relacionados, lo que se reflejó en que el flujo anual promedio de inversión extranjera ascendiera en el periodo 1994-2000 a 10,000 millones de dólares, comparado con el flujo anual promedio de únicamente 700 millones de dólares en el periodo 1971-1984. ${ }^{26}$ La tabla 4 (véase página siguiente) muestra claramente este crecimiento.

Los mismos datos, presentados gráficamente (véase gráfica en página posterior), permiten apreciar con mayor claridad la importancia creciente de la IED en el desarrollo del país. Debe destacarse, sin embargo, la tendencia a una disminución en los flujos a partir de 2002. Sin duda, las reformas estructurales incrementarían significativamente los flujos en los próximos años.

Una mirada más detallada al origen de los flujos de inversión muestra que estos provienen principalmente de los Estados Unidos de América (62.3\% del total acumulado 1994-2004). ${ }^{27}$ Canadá aporta el 3.4\% para constituir a América del Norte como la región económica más importante para México como fuente de inversión extranjera, seguida por la Unión Europea que representó el 24\%. Después de los Estados Unidos, los países individuales con mayor inversión acumulada en México durante el período 1994-2000 son España (8.3\%), Holanda (8.2\%), Reino Unido $(3.7 \%)$ y Canadá. Por todo lo anterior parecería necesario tomar medidas para alcanzar varios objetivos importantes. Por un lado, diversificar su origen, pero más importante fortalecer la posición competitiva de México para incrementar los flujos de IED y conservar la existente puesto que, como se ha mostrado captamos una proporción pequeña de los flujos y estamos en constante competencia con otros Estados y regiones.

26 Véase Kats, 2002, 132.

27 Datos de Secretaría de Economía, Dirección General de Inversión Extranjera, http://www. economia.gob.mx/pics/p/p1175/04-JUN.xls (consulta octubre 2004). 
Tabla 4. Inversión extranjera directa. Flujos anuales, 1971-2004

\begin{tabular}{|r|r|c|r|}
\hline Año & $\begin{array}{r}\text { Inversión } \\
\text { extranjera directa }\end{array}$ & Año & $\begin{array}{c}\text { Inversión } \\
\text { extranjera directa }\end{array}$ \\
\hline 1971 & 168.0 & 1988 & 3157.1 \\
\hline 1972 & 189.8 & 1989 & 2913.7 \\
\hline 1973 & 287.3 & 1990 & 4978.4 \\
\hline 1974 & 362.2 & 1991 & 9897.0 \\
\hline 1975 & 295.0 & 1992 & 8334.8 \\
\hline 1976 & 299.1 & 1993 & 4900.1 \\
\hline 1977 & 327.1 & 1994 & 15064.8 \\
\hline 1978 & 383.3 & 1995 & 9660.0 \\
\hline 1979 & 810.0 & 1996 & 9987.1 \\
\hline 1980 & 1622.6 & 1997 & 14230.9 \\
\hline 1981 & 1701.1 & 1998 & 12346.2 \\
\hline 1982 & 626.5 & 1999 & 13189.7 \\
\hline 1983 & 683.7 & 2000 & 16597.7 \\
\hline 1984 & 1442.2 & 2001 & $26,843.2$ \\
\hline 1985 & 1871 & 2002 & 14774.6 \\
\hline 1986 & 2424.2 & 2003 & 10783.4 \\
\hline 1987 & 3877.2 & $2004 *$ & 10292.0 \\
\hline
\end{tabular}

FUENTE: Dirección General de Inversión Extranjera, Secretaría de Economía. Las cifras proporcionadas no son comparables con las estadísticas sobre IED publicadas por la Secretaría de Economía respecto de los años anteriores a 1994 debido a que las metodologías utilizadas no son comparables. Sin embargo, para efectos de mostrar las grandes tendencias pueden ser, con precaución, utilizables.

* Valor enero-junio 2004. 
Gráfica. Flujos anuales de IED 1979-2004

Inversión Extranjera Directa - Flujos Anuales

1979-2004

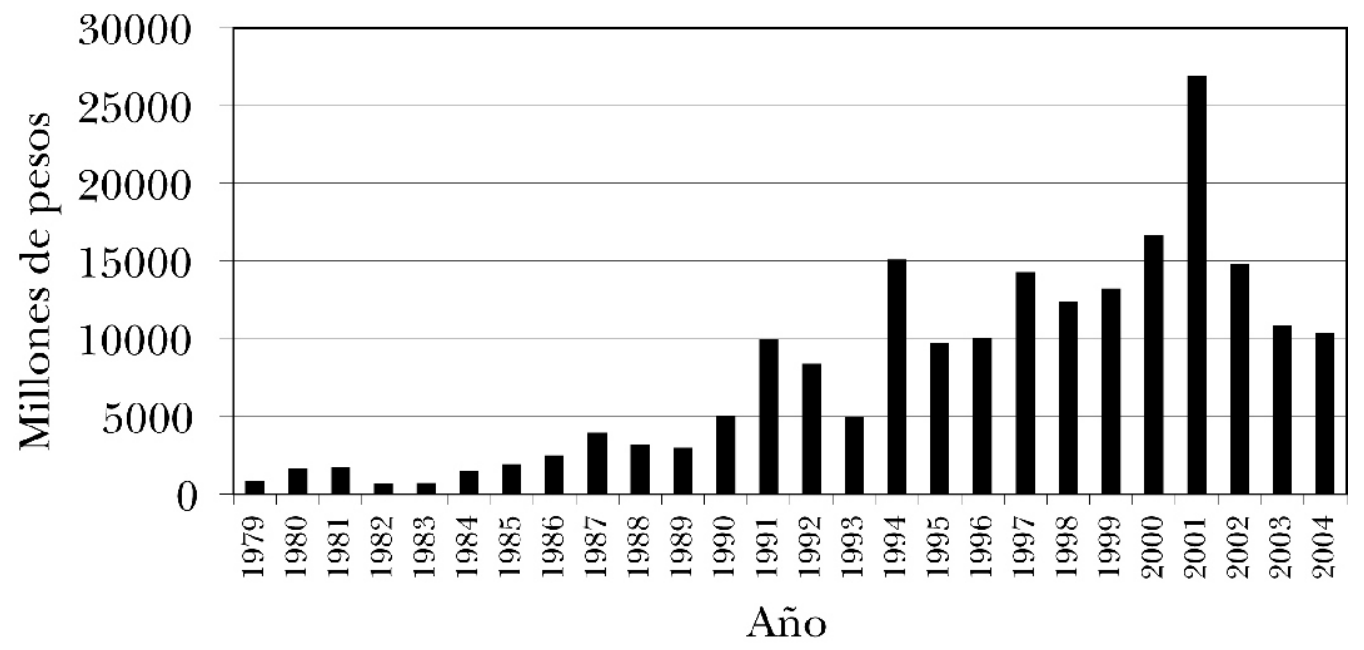

FUENTE: Elaboración propia, con datos de la Dirección General de Inversión Extranjera, Secretaría de Economía. 
La inversión juega un papel primordial en la actividad económica. Las necesidades de capital para el desarrollo de la infraestructura pública y de las empresas nacionales respecto de los flujos nacionales disponibles muestra con toda claridad que requerimos de flujos importantes de inversión extranjera para soportar el desarrollo de la economía nacional. La evaluación que la OCDE ha realizado sobre el papel de la IED en el desarrollo sostenido de los países en desarrollo como México permite evaluar con objetividad sus ventajas, pero también sus riesgos y la necesidad de lograr un equilibrio adecuado entre las necesidades de desarrollo nacional y el ambiente favorable para la inversión. ${ }^{28}$

Sin embargo es necesario destacar que existe una fuerte competencia entre las economías en desarrollo para atraer capitales externos. En otras palabras, sin un entorno económico, social y jurídico adecuado para la IED los capitales simplemente optan por otros países. Debe subrayarse que esta misma afirmación aplica al capital de origen nacional. La fragilidad del clima o entorno nacional para la inversión incrementa la vulnerabilidad de México en un entorno altamente globalizado y competitivo. Por ello, aunque pueda parecer paradójico, de la capacidad que tenga México para atraer, sostener e incrementar la inversión privada dependerá el fortalecimiento de su soberanía y sus tasas de crecimiento.

28 Los países en desarrollo, las economías emergentes y los países en transición han visto de manera creciente a la inversión extranjera directa como una fuente de desarrollo económico, crecimiento del ingreso y del empleo, así como de modernización. Los países han liberalizado sus regímenes de inversión extranjera directa y establecido otras políticas para atraer inversiones. Los beneficios globales de la inversión extranjera directa en los países en desarrollo están ampliamente documentados. Bajo las condiciones adecuadas y un nivel básico de desarrollo, la mayor parte de los estudios demuestran que la inversión extranjera directa dispara derramas en tecnología, apoya la formación de capital humano, contribuye a la integración comercial internacional, ayuda a crear un entorno competitivo para las empresas y mejora el desarrollo empresarial. Todo lo anterior contribuye al mayor crecimiento económico, que es el instrumento más poderoso para aliviar la pobreza. Más allá de los beneficios económicos, la inversión extranjera directa contribuye a mejorar el medio ambiente y las condiciones sociales, por ejemplo mediante la transferencia de tecnologías limpias y políticas corporativas socialmente responsables. Sin embargo, se reconoce también que existen preocupaciones sobre potenciales retrocesos, tanto económicos como no económicos, entre otros deterioro de la balanza de pagos cuando los beneficios son repatriados (aunque generalmente compensados por nueva inversión), falta de vínculos positivos con las comunidades locales, efectos potencialmente dañinos para el medio ambiente, especialmente en las industrias extractivas y pesadas, efectos sociales disruptivos y consecuencias en la competencia de los mercados nacionales. Más allá, algunos gobiernos de países receptores de inversión perciben una dependencia creciente de las empresas operadas internacionalmente como una pérdida de soberanía. Véase OECD. Foreing Direct Investment for Development. Maximising Benefits, Minimising Costs, París, OCDE, 2002, pp. 5 y 6. 


\section{MÉXICO Y EL DERECHO INTERNACIONAL DE LA INVERSIÓN EXTRANJERA}

\section{Criterios de trato}

Los criterios o estándares de trato a la inversión extranjera tienen su origen en el derecho consuetudinario internacional y un desarrollo importante en el derecho convencional internacional. Como se señaló en la sección introductoria se ha producido en los últimos veinte años un crecimiento importante de los APRI a nivel global y adoptados por México. La característica principal de estos acuerdos es que los Estados parte se comprometen a otorgar a los inversionistas extranjeros de la(s) otra(s) parte(s) del acuerdo un cierto tipo de trato que representa un estándar o criterio para evaluar la actividad gubernamental en su relación con el inversionista y su inversión. Los criterios de trato más comunes en el derecho internacional de la inversión extranjera son los de trato nacional, trato de nación más favorecida y trato mínimo. Aquí nos ocuparemos principalmente del análisis de este último criterio por ser el más relevante a la discusión de impacto en políticas nacionales para crear un clima y régimen favorable a la inversión.

¿Por qué? El principio de trato nacional consiste en que el Estado receptor de la inversión extranjera se compromete a brindar al inversionista o a su inversión el mismo trato que brinda o brindaría a un inversionista nacional o a su inversión situado en circunstancias similares. Por lo tanto este criterio se establece mediante la referencia directa a las medidas, regulación y procesos ya existentes en el régimen nacional. El objetivo de este criterio es evitar un trato diferenciado o discriminatorio en razón de la calidad de extranjero del inversionista. Sin embargo, si el régimen nacional es hostil a la inversión privada en general, o la desalienta u obstaculiza por cualquier razón, el criterio no es útil para el fortalecimiento del régimen por ser precisamente referencial. El criterio se cumple simplemente si el trato dado al inversionista extranjero es equivalente al que se otorgaría a un inversionista local, aún cuando en ambos casos desincentive la inversión privada.

Lo mismo aplica al caso del trato de nación más favorecida. Este criterio igualmente hace un reenvío, pero en este caso no al régimen nacional, sino al de un tercer Estado. El estándar de nación más favorecida significa que el Estado parte se compromete a extender al inversionista 
de la otra parte del acuerdo el mismo trato que observa con un inversionista de un Estado no parte del acuerdo, si este último trato es más favorable que el otorgado bajo el acuerdo respectivo al inversionista del Estado parte. Nuevamente podría darse el caso de que ni el trato otorgado a nivel nacional, ni el trato más favorable extendido a un tercer Estado representaran condiciones adecuadas para el desarrollo de las actividades de la inversión.

La respuesta histórica, a través del derecho internacional, ante la posible limitación del trato otorgado a nivel nacional lo constituye el nivel mínimo de trato. Este criterio es en realidad una aplicación de reciente aparición, a la materia de inversión extranjera, de las obligaciones consuetudinarias internacionales en materia de obligaciones generales de trato a los extranjeros. El nivel mínimo de trato propone un criterio autónomo al trato nacional o al trato otorgado a un tercer Estado. El nivel mínimo de trato es el estándar necesario para calificar a cierta actividad gubernamental, a la luz de las circunstancias relevantes, como propia de un gobierno de estado de derecho en su relación con la inversión o el inversionista extranjero. El contenido del nivel mínimo de trato corresponde más cercanamente con lo que en el derecho anglosajón constituye la noción sustantiva de debido proceso. Por lo tanto este estándar tiene que ver en cierta forma con principios de racionalidad, equidad, objetividad, imparcialidad y de relación razonable entre fines gubernamentales y medios escogidos.

Las principales críticas que se han vertido en contra del criterio mínimo de trato corresponden a calificativos de vaguedad, discrecionalidad e indefinición. Definitivamente el criterio no convive fácilmente con ciertas nociones formalistas y de la tradición codificada del sistema jurídico mexicano y de otros que pertenecen a la tradición continental. El propósito de este artículo no es tomar partido en ese debate y la crítica o defensa del estándar exceden los alcances del mismo. Nuestro propósito es más modesto: analizar el criterio, y la experiencia de su aplicación a controversias internacionales, y esbozar algunas reflexiones sobre su posible utilidad en la generación de un ambiente gubernamental más propicio a la inversión productiva. El criterio es parte ya del sistema jurídico mexicano a través de la diversidad de tratados en materia de inversión. La pregunta es qué se puede aprender de su aplicación en cuanto a la relación entre gobierno y capital privado. 
El nivel mínimo de trato en materia de inversión se ha expresado a su vez a través de dos estándares diferenciados. Por un lado el que se conoce como el criterio de trato justo y equitativo y por otro, el que se conoce como el criterio de protección y seguridades plenas. Por ejemplo, el artículo 1105 del TLCAN, precursor para México de la obligación, articula estos criterios de la siguiente manera: "Cada una de las Partes otorgará a las inversiones de los inversionistas de otra Parte, trato acorde con el derecho internacional, incluido trato justo y equitativo, así como protección y seguridad plenas".

Los Acuerdos de Protección Recíproca de Inversiones (APRI) aprobados por el Senado de la República y vigentes para México contienen generalmente una cláusula similar. ${ }^{29} \mathrm{El}$ alcance de estos criterios ha sido motivo de discusión jurisprudencial en el derecho internacional. Analizamos estos dos criterios en orden.

\section{Trato justo y equitativo y protección y seguridades plenas}

El estándar de trato justo y equitativo aplicado a la inversión extranjera encuentra su primera expresión convencional en la Carta de la Habana de 1948, en el primer intento por establecer una organización internacional del comercio. ${ }^{30}$ En la diversidad de los APRI que la incorporan desde la década de los años cincuenta se han utilizado intercambiablemente las palabras en inglés "fair" y "just", y algunos tratados utilizan únicamente la expresión "trato equitativo". En algunos tratados se ha expresado como una recomendación y no como obligación.

Si bien en este artículo partimos de la premisa de que el estándar "trato justo y equitativo y protección y seguridades plenas" es una manifestación del nivel mínimo de trato bajo el derecho internacional, se ha avanzado otra interpretación divergente. En particular otros autores han sostenido que el estándar es un criterio únicamente convencional, inde-

29 Véase por ejemplo el artículo 4 del Apri celebrado con Suiza, el párrafo 2 del artículo tercero del Apri celebrado con Argentina o el párrafo 3 del artículo 4 del Apri celebrado con Francia. Véase supra nota 18.

30 Posteriormente fue introducida en el Borrador de Convención Abs-Shawcros de 1960 y en el Borrador de Convención de Protección de la Propiedad en el Extranjero de la OECD de 1967. Véase Fair and Equitable Treatment, UNCTAD/ITE/IIT/11 (Vol. III), UNCTAD Series on issues in international investment agreements (United Nations, 1999), pp. 10, 11, 14-16. Sin embargo es en los Apri, especialmente en aquellos negociados por los EUA a partir de la década de 1960 que el estándar empieza a cobrar fuerza como obligación internacional convencional. 
pendiente del nivel mínimo de trato. ${ }^{31}$ En otras palabras que debe entenderse conforme a su significado ordinario. Esta interpretación presenta el problema de que el significado del criterio es inclusive aún más vago toda vez que la noción de justo y equitativo queda al arbitrio de una consideración únicamente subjetiva, además de que implica un rompimiento con la jurisprudencia internacional y pretende que la utilización y repetición de esta frase está más anclada en una decisión de equidad, conforme al significado que le da el artículo 38 del Estatuto de la Corte Internacional de Justicia, que a un criterio jurídico (el cual por supuesto puede tener un contenido de equidad en su expresión jurídica).

En el contexto del TLCAN la discusión de si el criterio reflejaba la institución del trato mínimo conforme al derecho consuetudinario o representaba un estándar convencional adicional e independiente del derecho consuetudinario internacional se ha presentado en diversos casos. ${ }^{32}$ La controversia para propósito del TLCAN fue resuelta por la Comisión de Libre Comercio en su interpretación de julio de 2001, contenida en el documento "Nota interpretativa de la Comisión de Libre Comercio del TLCAN (31 de julio de 2001)". ${ }^{33}$ De acuerdo con las aclaraciones emitidas por los tres ministros de comercio, la fracción 1 del artículo 1105 "no exige un nivel de trato adicional o superior al nivel mínimo de trato a extranjeros que estipula el derecho 'consuetudinario' internacional". ${ }^{34} \mathrm{~A}$ ello también se refiere la declaración que establece: "El hecho de que se determine que hubo una infracción de otra cláusula del TLCAN o de otro acuerdo internacional no implica que se haya infringido la fracción $1 \mathrm{del}$ artículo 1105". El propósito de la comisión, quien posee la facultad de interpretar las disposiciones del capítulo XI en forma vinculante para los tribunales arbitrales que se constituyen bajo el capítulo, es confirmar que las partes del tratado pretendieron que el nivel de trato contenido en el 1105 es aquel desarrollado en el derecho consuetudinario internacional.

¿Cuál es entonces el contenido de este criterio? Uno de los precedentes más relevantes en materia de inversión es sin duda el caso concer-

31 Véase, por ejemplo, Mann, F. A., "British Treaties for the Promotion and Protection of Investments", Further Studies in International Law, Oxford Clarendon Press, 1990.

32 Véase los casos de Methanex, S. D. Myers y Metalclad presentados ante tribunales arbitrales al amparo del TLCAN, especialmente en cuanto a los alegatos de los demandantes.

33 Veáse la nota, disponible en http://www.economia-snci.gob.mx/sic\%5Fphp/ls23al.php?s= $18 \& p=1 \& l=1$.

34 Idem. 
niente a ELSI ante la Corte Internacional de Justicia entre los Estados Unidos e Italia. ${ }^{35}$ Estados Unidos reclamó a Italia haber violado sus obligaciones bajo el Tratado de Amistad, Comercio y Navegación (en adelante FCNT, por sus siglas en inglés) de 1948. Una de las obligaciones reclamadas era la contenida en el artículo I del Tratado Supletorio del FCNT. Si bien el artículo I del Tratado Supletorio del FCNT no incluía las palabras "trato justo y equitativo", sino más bien prohibía "medidas arbitrarias o discriminatorias" la decisión de la corte es relevante toda vez que los tratados de amistad, comercio y navegación constituyen la generación de acuerdos internacionales inmediatamente predecesores de los acuerdos de promoción recíproca de inversiones y la litis fue directamente relevante a las obligaciones de trato que el gobierno de Italia debía a los inversionistas estadounidenses en su territorio. El presupuesto central para relacionar la decisión de la CIJ es que trato arbitrario y trato justo son exactamente opuestos tratándose de medidas gubernamentales que afecten a particulares, en este caso a inversionistas extranjeros bajo el derecho internacional.

En el caso, la empresa ELSI de inversión estadounidense, fue intervenida temporalmente por el gobierno municipal de Palermo, Italia, bajo la invocación de ciertas facultades de ley, toda vez que la empresa, al no haber podido cumplir con sus obligaciones financieras, fue sujeta de un paro laboral y de la toma de sus instalaciones por parte de los trabajadores. El gobierno local de Palermo actuó con el fin de evitar un problema social mayor en una región que dependía en gran parte de la fuerza laboral de ELSI. La decisión del gobierno de Palermo fue atacada ante los tribunales italianos por ELSI, en donde eventualmente se determinó que la resolución de intervención estaba afectada de ilegalidad en el plano administrativo. En uno de los párrafos más relevantes de la decisión, la CIJ explica que la determinación de ilegalidad de la resolución municipal bajo el derecho local no necesariamente implica una violación jurídica en el plano internacional. La corte explica que equiparar ilegalidad en el derecho nacional con arbitrariedad en el plano internacional simplemente destituye de todo significado a la obligación internacional. ${ }^{36}$ Más adelante la corte señala:

35 Case Concerning Eletronica Sycula S.p.A. (ELSI) (United States of America v. Italy), I.C.J. (July 1989).

36 ELSI, párr. 124. 
Arbitrariness is not so much something opposed to a rule of law, as something opposed to the rule of law. This idea was expressed by the Court in the Asylum case, when it spoke of "arbitrary action" being substituted for "the rule of law" (Asylum Judgment, IC.J. Reports 1950, p. 284). It is a willful disregard of due process of law, an act which shocks or at least surprises, a sense of juridical propriety. ${ }^{37}$

La CIJ hizo un análisis muy cuidadoso de las razones y circunstancias bajo las cuales actuó el gobierno municipal de Palermo para concluir que, en los hechos, independientemente de la determinación de los tribunales nacionales sobre la calificación del acto en el derecho público y administrativo italiano, las medidas no se elevaban a un acto arbitrario - un trato injusto o inequitativo - en derecho internacional. Es sumamente importante el análisis de los hechos del caso. El gobierno municipal había actuado bajo una interpretación razonable de sus facultades, las había ejercido en forma adecuada, bajo las circunstancias, y nada en los hechos representaba un actuar que desestimara las nociones sustantivas del debido proceso y de apego al estado de derecho. Esta interpretación es además respetuosa de la distinción entre los órdenes nacional e internacional. El tribunal internacional no es un tribunal de apelación de las decisiones locales.

En ELSI, la CIJ también analizó un alegato de violación al criterio de "protección y seguridades plenas". Ese análisis de la corte también es importante para entender el alcance del trato mínimo a los inversionistas en el derecho internacional. Sobre ese criterio el tratado entre Italia y los Estados sí contemplaba la frase "protección y seguridades plenas". ${ }^{38} \mathrm{El}$ criterio se puede encontrar en los APRI y otros tratados, ya sea en el mismo párrafo en el que se establece el de trato justo y equitativo, como es el caso del artículo 1105 del TLCAN, en artículo diverso, o en forma exclusiva. Las expresiones "protección y seguridades plenas", "más constante protección y seguridad", "protección y seguridad constante" y similares, se utilizan de forma intercambiable en el derecho internacional convencional, pero denotan un contenido específico conforme a éste. Este tipo de expresiones es lo que la Convención de Viena sobre el Derecho de los Tratados, de la cual México es parte, denomina un término

38 Tratado de Amistad, Comercio y Navegación entre Italia y los Estados Unidos, 1er. párrafo, artículo $\mathrm{V}$. 
con sentido especial. Es decir el término descrito tiene un sentido especial en el derecho internacional y debe interpretarse en ese sentido y no de forma literal.

La disposición no significa que el Estado se está obligando a garantizar absolutamente la inversión, como se ha intentado argumentar en algunos casos. Esta disposición no constituye una obligación financiera en el sentido de un aval, ni la promesa de asumir tal obligación financiera en relación con los riesgos normales y externos de todo proyecto de inversión. Este estándar de trato consiste en que el Estado se compromete a actuar con la debida diligencia, de conformidad y en la extensión de las facultades propias y ordinarias de un gobierno, en su relación con los inversionistas extranjeros y sus inversiones.

En ELSI la CIJ nuevamente concluyó que Italia no había violado su obligación de proveer protección y seguridades plenas al inversionista estadounidense. En referencia a la ocupación de la planta por los trabajadores de ELSI, la corte explicó que: "La disposición de protección y seguridad constante [plena] no puede ser interpretada como la extensión de una garantía en el sentido de que la propiedad bajo ninguna circunstancia será ocupada o afectada". 39

Otros precedentes internacionales que han elaborado sobre la interpretación de la disposición en ELSI, explican que conforme a derecho internacional la frase "protección y seguridades plenas" o similares, no reflejan una responsabilidad estricta del Estado en el sentido de que se constituya como asegurador o garante de las inversiones o propiedades, sino que demanda únicamente que el Estado actúe con la debida diligencia en relación con esas inversiones o propiedades. ${ }^{40}$ Esto significa que para demostrar que los actos del Estado violan una disposición de ese tipo debe probarse que el Estado, a través de sus órganos de gobierno, actuó en forma negligente, causando como consecuencia daño a la propiedad o inversión protegida bajo el estándar en el tratado respectivo.

Así, la obligación de protección y seguridad plena y constante que asume el Estado mexicano significa que en el ejercicio gubernamental ordinario, conforme al derecho mexicano, deberán evitarse actos que en forma negligente pongan en peligro o impidan la preservación de la ca-

39 ELSI, párrafo 108.

40 Véase, por ejemplo, In the Matter of Arbitration between Asian Agricultural Products Ltd. (AAPL) v. Republic of Sri Lanka (Final Award, June 27, 1990) ICSID, Case No. ARB/87/3, reproduced at 30 I.L.M. 577 (en adelante "AAPL"). 
pacidad de los proyectos de inversión para su instalación y desarrollo. En síntesis la obligación no implica compromiso alguno del gobierno mexicano de actuar como fiador o garante financiero último de las inversiones. En otras palabras, si el proyecto fracasa por malos manejos del inversionista, mala estrategia de negocios, por riesgos de inversión y circunstancias económicas o sociales ajenas a cualquier acto gubernamental, el Estado mexicano no tendría ninguna responsabilidad u obligación derivada del estándar.

Otro precedente relevante es el del caso AAPL v. Sri Lanka. ${ }^{41}$ Ahí un tribunal arbitral constituido bajo la Convención del CIADI, determinó que el gobierno de Sri Lanka violó la obligación de protección y seguridades plenas. Los hechos del caso son los siguientes. Un grupo inversionista de Hong Kong constituyó una empresa, AAPL, en Sri Lanka, para cultivar y exportar camarones. Las instalaciones se encontraban en una zona en la que operaban las fuerzas rebeldes tamiles. El ejército de Sri Lanka organizó y llevó a cabo un operativo de contrainsurgencia, que derivó en un enfrentamiento entre las fuerzas gubernamentales y los rebeldes tamiles en la granja camaronera, en el que las instalaciones de la empresa fueron destruidas y se perdieron vidas del personal de la misma. El tribunal resolvió que el gobierno actuó negligentemente al ignorar y desestimar los intentos realizados por los directivos de la empresa para cooperar con el gobierno en relación con el conflicto con los tamiles, quienes el gobierno presumía estaban infiltrados en la empresa. Asimismo el tribunal determinó que el gobierno había actuado negligentemente y por lo tanto en violación a su obligación de otorgar protección y seguridades plenas, al no dar aviso a los directivos de la empresa acerca de la realización del operativo militar, lo cual hubiera permitido a la empresa mover equipo e instalaciones delicadas fuera de la granja, y por supuesto, hubiera evitado la pérdida innecesaria de vidas. El estándar de protección y seguridades plenas tiene una relación cercana con el estándar de trato mínimo que en algún momento se conoció equivocadamente como responsabilidad indirecta del Estado en la protección de extranjeros. Este criterio, del cual existen múltiples precedentes en el derecho internacional, parte del principio de que el Estado no es responsable internacionalmente por actos no imputables a sus servidores públicos, pero sí lo es por su negligencia en la prevención o respuesta a tales actos. Así, por ejem- 
plo, el Estado no puede ser responsable del homicidio de un extranjero a manos de un particular, pero sí puede ser responsable si omite negligentemente investigarlo y en su caso perseguir el delito.

\section{El criterio y las controversias en el caso de México}

Desde la adopción del TLCAN y otros APRI y hasta la fecha, México ha defendido siete controversias ante tribunales internacionales por reclamaciones de inversionistas extranjeros que han concluido con un laudo: Metalclad, ${ }^{42}$ Azinian, ${ }^{43}$ Waste Management I I4 y II, ${ }^{45}$ Feldman, ${ }^{46}$ GAMI $^{47}$ y Tecmed. ${ }^{48}$ Seis de esas controversias fueron presentadas por inversionistas estadounidenses al amparo del capítulo XI del TLCAN. Únicamente el caso Tecmed fue presentado por un inversionista español al amparo del APRI entre México y ese país. En tres de los siete casos, Metalclad, Tecmed y Feldman, los tribunales arbitrales han resuelto que México ha violado alguna disposición de los tratados respectivos. Los otros cuatro casos han sido desechados por los tribunales sin encontrar responsabilidad para México, aunque es relevante señalar que Waste Management I y II, fueron avanzados por el mismo inversionista demandante sobre la base de los mismos hechos. ${ }^{49}$ En el caso de Metalclad y Tecmed los tribunales arbitrales respectivos determinaron que México violó el criterio de trato justo y equitativo. ${ }^{50}$

42 Metalclad Corporation c. Estados Unidos Mexicanos (Laudo, agosto 30, 2000), Caso Núm. $\mathrm{ARB}(\mathrm{AF}) / 97 / 1$.

43 Robert Azinian, Kenneth Davitian y Ellen Baca c. Estados Unidos Mexicanos (Laudo, noviembre 1, 1999), Caso Núm. ARB(AF)/97/2.

44 Waste Management Inc. c. los Estados Unidos Mexicanos (Laudo sobre Jurisdicción, junio 2, 2000), Caso Núm. ARB(AF)/98/02.

45 Waste Management Inc. c. los Estados Unidos Mexicanos (Laudo, abril 30, 2004) Caso Núm. ARB(AF)/00/03.

46 Marvin Feldman c. los Estados Unidos Mexicanos, (Laudo, diciembre 16, 2002), Caso No. $\mathrm{ARB}(\mathrm{AF}) / 99 / 1$.

47 GAMI Investments Inc. c. los Estados Unidos Mexicanos (Laudo, noviembre 15, 2004), Procedimiento conforme al capítulo XI del TLCAN y el Reglamento de Arbitraje de la CNUDMI.

48 Técnicas Medioambientales Tecmed S.A. c. Estados Unidos Mexicanos (Laudo, 29 de mayo de 2003), Caso No. ARB(AF)/00/2.

49 El caso Waste Management I fue desechado sobre la base de falta de competencia del Tribunal Arbitral toda vez que la empresa demandante no renunció a un procedimiento arbitral paralelo en curso en el que podía ser beneficiario de un laudo por daños. En Waste Management II, un nuevo Tribunal Arbitral entró a resolver la reclamación sustantiva una vez que el inversionista demandante presentó su demanda de conformidad con lo requisitos de la sección B del capítulo XI.

50 En el caso Feldman la violación fue al criterio de trato nacional bajo el artículo 1102 del TLCAN. 
Metalclad fue el primer laudo contrario a una de las partes del TLCAN emitido bajo el mecanismo del capítulo XI. El tribunal en Metalclad determinó que México violó la obligación del nivel mínimo de trato contenida en el artículo 1105. La empresa estadounidense había adquirido a través de una subsidiaria mexicana un sitio en San Luis Potosí en el que pretendió abrir un confinamiento de residuos peligrosos. Uno de los puntos centrales del litigio fue si la empresa requería un permiso municipal de construcción, si existía el procedimiento para obtenerlo, y si en todo caso el ayuntamiento tenía facultades para negar el permiso municipal de construcción sobre la base de consideraciones ambientales. La sociedad propietaria del predio y posteriormente adquirida por Metalclad había solicitado y se le había negado el permiso en 1991. La sociedad volvió a solicitar el permiso en noviembre de 1994, ya siendo propiedad de Metalclad. El ayuntamiento negó el permiso nuevamente en diciembre de 1995.

En su decisión, el Tribunal Arbitral determinó que no era claro si Metalclad requería de un permiso municipal de construcción ${ }^{51}$ pero que, aún concediendo que requería de uno, la legislación y procedimientos eran tan opacos que violaban las obligaciones a cargo de México en materia de publicidad de leyes y regulaciones de conformidad con el capítulo 18 del TLCAN. Finalmente que, en cualquier caso, el ayuntamiento carecía de facultades para negar el permiso sobre la base de consideraciones ambientales. ${ }^{52} \mathrm{Si}$ bien el tribunal no lo refirió explícitamente, los párrafos 90 y 91 del laudo sugieren que la decisión de las autoridades municipales fue contraria al debido proceso y políticamente motivada. Una premisa importante en la decisión del tribunal fue su hallazgo de hechos de que la empresa estadounidense actuó "prudentemente y en plena expectativa de que el permiso le sería concedido" sobre la base de las seguridades otorgadas verbalmente por autoridades federales. Estas conclusiones constituyeron la base de la determinación de violación al trato mínimo bajo el artículo 1105.

Sin embargo, la decisión en Metalclad en cuanto a este punto fue anulada por el tribunal superior de Columbia Británica, sede del arbitraje. El juez canadiense, en el procedimiento de nulidad del laudo iniciado por México, resolvió que el Tribunal Arbitral se había excedido en su ju-

51 Véase laudo párrafos 76 y 99.

52 Véase laudo párrafos 81-86, 92. 
risdicción (competencia) al encontrar que la violación de una disposición del TLCAN (en el capítulo XVIII), que no se encuentra dentro del capítulo XI, podía dar lugar a una violación de alguna de las disposiciones sustantivas del capítulo XI.

En el caso Tecmed, el Tribunal Arbitral determinó que México violó la obligación de "trato justo y equitativo conforme al derecho internacional" establecida en el artículo 4(1) del APRI entre los Estados Unidos Mexicanos y España. ${ }^{53}$ Este caso constituye el segundo que se presenta contra México en relación con un inversionista extranjero en el área de confinamiento de residuos peligrosos. A diferencia de Metalclad, aquí el tribunal resolvió que la violación era atribuible al gobierno federal, específicamente a la actuación del Instituto Nacional de Ecología (INE). En síntesis los hechos del caso se refieren a la cancelación del permiso de operación de un confinamiento propiedad de la empresa española, a través de una subsidiaria mexicana, que se encontraba en las afueras de la ciudad de Hermosillo, Sonora. El cierre del confinamiento se produjo en el contexto de presiones de la sociedad civil en ese Estado.

En su determinación, el tribunal definió que el término "trato justo y equitativo" es "parte constitutiva y una expresión del principio de buena fe reconocido por el derecho internacional". ${ }^{54}$ El criterio, en palabras del tribunal demanda:

De las Partes Contratantes del Acuerdo brindar un tratamiento a la inversión extranjera que no desvirtúe las expectativas básicas en razón de las cuales el inversor extranjero decidió realizar su inversión. Como parte de tales expectativas, aquél cuenta con que el Estado receptor de la inversión se conducirá de manera coherente, desprovista de ambigüedades y transparente en sus relaciones con el inversor extranjero, de manera que éste pueda conocer de manera anticipada, para planificar sus actividades y ajustar su conducta, no sólo las normas o reglamentaciones que regirán tales actividades, sino también las políticas perseguidas por tal normativa y las prácticas o directivas administrativas que les son relevantes. Un accionar del Estado ajustado a tales criterios es, pues, esperable, tanto en relación con las pautas de conducta, directivas o requerimientos impartidos, o de las resoluciones dictadas de conformidad con las mismas, cuanto con las razones y finalidades que las subyacen. El inversor extranjero también

53 Acuerdo entre los Estados Unidos Mexicanos y el Gobierno del Reino de España para la Promoción y Protección Recíproca de Inversiones, DOF, 19 de marzo de 1997.

54 Laudo Tecmed, párrafo 153. 
espera que el Estado receptor actuará de manera no contradictoria; es decir, entre otras cosas, sin revertir de manera arbitraria decisiones o aprobaciones anteriores o preexistentes emanadas del Estado en las que el inversor confió y basó la asunción de sus compromisos y la planificación y puesta en marcha de su operación económica y comercial [énfasis añadido.$^{55}$

Más adelante, en ese mismo párrafo, y citando el caso Neer de 1926 de la Comisión Mixta de Reclamaciones México-Estados Unidos y el caso ELSI, el tribunal señala que el criterio se viola cuando las medidas atribuibles al Estado obligado son arbitrarias conforme lo reconocería todo ser humano "razonable e imparcial" y, aún cuando no violen normas jurídicas específicas sean contrarias a derecho porque "shocks or at least surprises a sense of juridical propriety". ${ }^{56}$

En el caso específico, en la resolución del tribunal, ello sucedió en el momento en que la empresa operadora del confinamiento accedió a reubicar el mismo a condición de que pudiera operar hasta que el nuevo confinamiento estuviese aprobado en el sitio que determinara la autoridad federal ambiental, la misma nunca le advirtió que la propuesta no sería considerada, y en cambio le notificó la cancelación del permiso, aduciendo violaciones a las normatividad ambiental, sin una oportunidad razonable en tiempo y forma para poder remediar las mismas o cumplir con las expectativas gubernamentales. El tribunal determinó que la clausura tuvo más bien una motivación política y no de prevención o protección del medio amiente, y que se tomó a consecuencia de la presión social. Por lo tanto, el tribunal señala que la actuación del Instituto Nacional de Ecología violentó

La justa expectativa de la demandante [de] que la normativa mexicana que regía aquélla, y las facultades de supervisión, control, prevención y sanción que esa normativa confiere a las autoridades encargadas de administrar dicho régimen, serían utilizadas con la finalidad de asegurar que los objetivos de protección ambiental, de la salud humana y del equilibrio ecológico que la animaban fuesen respetados. ${ }^{57}$ 
Si vemos el conjunto de casos que han avanzado a un laudo definitivo de un tribunal arbitral en contra de México en materia de derecho internacional de la inversión extranjera, resalta que cuatro de ellos (considerando a Waste Management I y II como el mismo caso en los hechos), se refieren a conflictos en el contexto de la materia ambiental y en relación con la industria de recolección de desechos. Otro de los denominadores comunes es la existencia de un conflicto socio-político que subyace y es en cierto modo determinante del conflicto que da origen a la reclamación. Ello se presenta en todos los casos con excepción del de Marvin Feldman que se refiere a una controversia derivada de una situación de derecho fiscal personal del inversionista demandante y, de su negocio, bastante peculiar, por no decir extraña, y compleja. ${ }^{58}$

Si bien cuatro de los casos fueron defendidos exitosamente por México ante los tribunales arbitrales, el análisis conjunto de los hechos de aquellos que se han avanzado al arbitraje revelan, en mayor o menor medida, falta de coordinación entre autoridades gubernamentales, falta de previsión y de políticas adecuadas para el manejo de los conflictos sociales y políticos que subyacen a las controversias, incongruencia en el ejercicio de facultades y atribuciones de los órganos de gobierno, debilidad de las mismas facultades y atribuciones gubernamentales para el manejo de los conflictos, así como debilidad en la comunicación clara de las políticas y decisiones tanto a inversionistas, como a otros actores involucrados. Se han esbozado algunas críticas ante las demandas perdidas por el gobierno de México, en especial en relación con el laudo en Metaclald que condenó a México al pago de alrededor de 15 millones de dólares. Sin embargo, poco se ha reflexionado sobre los conflictos y la actuación gubernamental previa y que dio origen a la presentación de las reclamaciones ante los tribunales arbitrales. Si bien en la materia ambiental, tanto el caso Metalclad, como el Tecmed han influido en la adecuación de políticas públicas en el área de confinamiento de residuos peligrosos, éstas todavía han sido insuficientes para generar en el país un crecimiento importante en la industria que pueda cumplir con la demanda de estos

58 En el caso de Feldman, el inversionista se dedicaba a la exportación de cigarros que adquiría principalmente en almacenes de venta al público. Feldman solicitaba entonces la devolución del Impuesto Especial a la Producción y Servicios, originalmente diseñado para beneficiar al productor-exportador de cigarros y no al comprador en punto de venta al público nacional en general. Feldman logró algunas devoluciones del impuesto de la autoridad hacendaria pero toda vez que no podía recibir factura con desglose del IEPS, las devoluciones fueron negadas. 
servicios a nivel nacional. Si echamos un vistazo muy rápido al reciente conflicto y fracaso del gobierno federal en el proyecto del nuevo aeropuerto para la ciudad de México, encontramos nuevamente muchos de los rasgos de debilidad institucional y de coordinación política que subyacen en muchas de las controversias que se han avanzado en contra de México ante tribunales internacionales. Es claro que el nuevo entorno federal, de competencia política y de participación social en el país exige mayor capacidad de coordinación, previsión, diseño e instrumentación de políticas públicas, que incluye necesariamente la utilización más eficaz o adecuación, de los instrumentos de política jurídica de la administración pública en general. Poner el énfasis en los problemas y conflictos que se enfrentan y se busca resolver, entre ellos el de generar un ambiente propicio para la actividad productiva y su relación con la actuación y facultades de la administración gubernamental como un servicio público que debe considerar y coadyuvar a balancear y resolver intereses muchas veces divergentes, debe ser el eje de la reflexión y no el de los procedimiento y normatividad legal existente en abstracto.

\section{Libre convertibilidad y balanza de pagos}

Las obligaciones internacionales sobre inversión en materia de libre convertibilidad y movilidad se refieren fundamentalmente a la posibilidad de convertir a cualquier divisa fuerte, los ingresos y ganancias derivadas de la inversión de los inversionistas extranjeros amparados por el tratado respectivo y poder transferirlos libremente a un Estado extranjero, ya sea para cubrir obligaciones, o simplemente para repatriar las ganancias. Por ejemplo, el artículo 1109 del TLCAN establece:

Cada una de las Partes permitirá que todas las transferencias relacionadas con la inversión de un inversionista de otra de las Partes en territorio de la Parte, se hagan libremente y sin demora. Dichas transferencias incluyen:

(a) ganancias, dividendos, intereses, ganancias de capital, pagos por regalías, gastos por administración, asistencia técnica y otros cargos, ganancias en especie y otros montos derivados de la inversión;

(b) productos derivados de la venta o liquidación, total o parcial, de la inversión;

(c) pagos realizados conforme a un contrato del que sea parte un inversionista o su inversión, incluidos pagos efectuados conforme a un convenio de préstamo; 
(d) pagos efectuados de conformidad con el Artículo 1110; y

(e) pagos que provengan de la aplicación de la Sección B.

2. En lo referente a las transacciones al contado (spot) de la divisa que vaya a transferirse, cada una de las Partes permitirá que las transferencias se realicen en divisa de libre uso al tipo de cambio vigente en el mercado en la fecha de la transferencia.

Esta disposición es equivalente a las contenidas en otros instrumentos internacionales firmados por México y aprobados por el Senado de la República. Entre otros cabe mencionar el Convenio Constitutivo de la Corporación Interamericana de Inversiones, los Tratados de Libre Comercio con el Grupo de los Tres, Bolivia, Costa Rica, Nicaragua, Chile y Bolivia, así como los artículos aplicables de la mayoría de los Acuerdos Recíprocos de Promoción y Protección a la Inversión celebrados por México. ${ }^{59}$

México adoptó, desde hace casi una década, un esquema de libre convertibilidad que eliminó restricciones y la intervención del Estado en la fijación del tipo de cambio. Por otro lado, diversas disposiciones de instrumentos internacionales, que son parte integrante del derecho nacional, han establecido ya la garantía de libre convertibilidad. Lo anterior es congruente con la política cambiaria que, de conformidad con la legislación aplicable, corresponde al Banco de México y a la Comisión de Cambios. Las excepciones incluidas en el artículo 1109, por ejemplo, salvaguardan además la aplicación de disposiciones que, por razones de interés público, pudieran implicar limitaciones en las operaciones de trans-

59 Así, por ejemplo, el artículo 6 del APRI entre los EUM y la República Federal de Alemania establece en su artículo 6 que: 1. Cada Estado Contratante garantizará que todo los pagos relacionados con una inversión de nacionales o sociedades del otro Estado Contratante puedan ser libremente transferidos, especialmente: a) del capital y de las sumas adicionales para el mantenimiento o ampliación de la inversión; b) de las rentas; c) de la amortización de préstamos; d) del producto de la inversión en caso de liquidación o enajenación total o parcial; e) de las indemnizaciones previstas en los Artículos 4 y 5. 2. Las transferencias conforme al Artículo 4, párrafo 2, así como a los artículos 5,6 o 7, se efectuarán sin demora, al tipo de cambio vigente en el mercado en la fecha de la transferencia. 3. No obstante lo dispuesto en los párrafos 1 y 2, los Estados Contratantes podrán impedir la realización de transferencias mediante la aplicación equitativa, de buena fe y no discriminatoria de sus leyes y reglamentos, en caso de protección de los derechos de los acreedores, emisión, comercio y operaciones de valores, reportes de transferencias de divisas $\mathrm{u}$ otros instrumentos monetarios, y como garantía del cumplimiento de las sentencias en procedimientos civiles, administrativos y penales. 4. En ausencia de un mercado cambiario, la cotización que se utilizará será la más reciente cotización cambiaria para la conversión de divisas a derechos especiales de giro. 
ferencias, tales como protección de los derechos de los acreedores, emisión, comercio y operaciones de valores, reportes de transferencias de divisas $\mathrm{u}$ otros instrumentos monetarios, y como garantía del cumplimiento de las sentencias en procedimientos civiles, administrativos y penales.

Por otro lado, una de las excepciones más generales a la movilidad de los capitales es la excepción en materia de balanza de pagos. Esta excepción implica lo siguiente:

a) El derecho soberano del Estado de adoptar medidas restrictivas a la convertibilidad monetaria y las transferencias de pagos en caso de afrontar dificultades fundamentales, o amenazas inminentes, a su balanza de pagos;

b) La obligación de:

- Imponer dichas medidas de manera equitativa, no discriminatoria y por un tiempo limitado que no debe ser más allá de lo necesario para remediar la situación de la balanza de pagos.

- Informar de las medidas que se tomen y de su eventual eliminación.

- Adoptar dichas medidas de conformidad con otras obligaciones internacionales contraídas previamente por el Estado.

El análisis y valoración de esta excepción debe ser realizado a la luz de las obligaciones particulares adquiridas por México en diversos instrumentos internacionales. Resultan especialmente relevantes aquellas disposiciones contenidas en los artículos XII y XIV del Acuerdo General sobre Aranceles Aduaneros y Comercio (GATT); el Entendimiento relativo a las disposiciones del Acuerdo General sobre Aranceles Aduaneros y Comercio de 1994 en materia de balanza de pagos; el artículo 2104 del Tratado de Libre Comercio de América del Norte; los artículos aplicables del Convenio Constitutivo del Fondo Monetario Internacional; el artículo 31 de la Decisión 2/2001 del Consejo Conjunto México-Unión Europea derivada del Acuerdo de Asociación Económica, Concertación Política y Cooperación entre los Estados Unidos Mexicanos y la Comunidad Europea y sus Estados Miembros y finalmente diversas disposiciones contenidas en los Acuerdos de Promoción y Protección Recíproca de las Inversiones firmados entre México y diversos países miembros de la Unión Europea. En esencia, todas estas disposiciones reconocen el derecho del Estado mexicano de imponer restricciones a la convertibilidad 
monetaria y a las transferencias de pagos en casos de que afronte problemas serios, actuales o inminentes, en su balanza de pagos. Sin embargo este derecho soberano se debe ejercer conforme algunas disciplinas que garantizan que estas medidas restrictivas se aplicaran de manera equitativa, no discriminatoria y por un tiempo limitado, suprimiéndolas tan pronto como sea posible.

Por ejemplo, el artículo 31 de la Decisión 2/2001 del Consejo Conjunto México-Unión Europea derivada del Acuerdo de Asociación Económica, Concertación Política y Cooperación entre los Estados Unidos Mexicanos y la Comunidad Europea y sus Estados Miembros refleja tales disciplinas de la siguiente manera:

Artículo 31. Dificultades en la balanza de pagos.

1. Cuando México o uno o más de los Estados Miembros enfrenten dificultades fundamentales de balanza de pagos, o una amenaza inminente de la misma, México, o la Comunidad o el Estado Miembro de que se trate, según sea el caso, podrán adoptar medidas restrictivas con respecto a pagos, incluyendo transferencias de montos por conceptos de liquidación total o parcial de inversión directa. Tales medidas deberán ser equitativas, no discriminatorias, de buena fe, de duración limitada y no irán más allá de lo que sea necesario para remediar la situación de balanza de pagos.

2. México, o la Comunidad o el Estado Miembro de que se trate, según sea el caso, informará a la otra Parte sin demora y presentará, lo más pronto posible, un calendario para su eliminación. Dichas medidas deberán ser tomadas de acuerdo con otras obligaciones internacionales de la Parte de que se trate, incluyendo aquellas al amparo del Acuerdo de Marrakech por el que se establece la OMC y los Artículos Constitutivos del Fondo Monetario Internacional (énfasis añadido).

El caso de la libertad del movimiento de los capitales y de una política macroeconómica clara en cuanto a la libre convertibilidad y su condicionamiento bajo la excepción de la balanza de pagos no es más que un ejemplo que contrasta con las reflexiones sobre la debilidad en aspectos micro de coordinación entre poderes públicos a las que se hizo alusión en la sección anterior. Estas políticas, que se sustentan en una consistencia ya transexenal de finanzas públicas sanas y políticas monetarias estables y claras, han sido uno de los factores que sin duda han contribuido positivamente a la atracción y permanencia de capitales productivos tanto nacionales como extranjeros en el país. En gran medida son resultado de las 
reformas estructurales que dieron origen al Banco de México, como un organismo público independiente de las facultades del Ejecutivo federal, y a la profesionalización del sector hacienda del gobierno federal.

\section{Régimen fiscal de los inversionistas extranjeros y de organismos internacionales}

El régimen fiscal de los inversionistas extranjeros es en principio el mismo aplicable a un inversionista nacional. La excepción la constituyen los tratados bilaterales en materia de doble tributación, que a través del principio de reciprocidad internacional, evitan que un extranjero pague impuestos equivalentes tanto en su lugar de residencia como en el sitio de su inversión. Para efectos prácticos, las disposiciones de estos tratados constituyen una exención impositiva dentro del régimen fiscal mexicano. Se justifican por el hecho de evitar la doble tributación, promover así la inversión extranjera, y permitir el mismo derecho a los nacionales inversores o residentes temporales en el Estado parte extranjero.

Recientemente se ha cuestionado si las exenciones fiscales a personas físicas o morales extranjeras son constitucionales. Por ejemplo, el Acuerdo Marco de Cooperación Financiera entre los Estados Unidos Mexicanos y el Banco Europeo de Inversiones, tratado firmado por México y enviado al Senado de la República para su análisis y aprobación, contiene un artículo que establece lo siguiente: "Artículo 4. El Banco estará exento de impuestos federales directos, en relación con los activos y rentas que se utilicen u obtengan por las actividades contempladas en el presente Acuerdo". 60

En otras palabras, el tratado pretende exentar del pago de impuestos al Banco Europeo de Inversiones en relación con los activos que utilice para realizar sus préstamos en México, así como de los ingresos que obtenga derivados de los mismos. ¿Es inconstitucional la exención de impuestos a una persona moral extranjera? En particular, se ha expresado que una disposición de ese tipo violaría el artículo 28 de la Constitución federal. Sostenemos que no es así.

El artículo 28 constitucional en su parte aplicable a la cuestión en análisis establece: "En los Estados Unidos Mexicanos quedan prohibidos

60 Por su parte, el artículo 2 del mismo acuerdo establece que "impuesto" comprenderá el Impuesto sobre la Renta y el Impuesto al Activo o aquellos que lo sustituyan. 
los monopolios, las prácticas monopólicas, los estancos y las exenciones de impuestos en los términos y condiciones que fijan las leyes. El mismo tratamiento se dará a las prohibiciones a título de protección a la industria".

Esta disposición constitucional ha sido interpretada en una diversidad de decisiones de la Suprema Corte. Es importante destacar que para propósitos del supuesto en discusión es claro que la corte ha señalado que dichas exenciones de impuestos sólo pueden realizarse mediante "normas con la jerarquía de la ley formal y material". ${ }^{61}$ Tanto el Código Fiscal de la Federación, como los tratados internacionales, constituyen normas con la jerarquía de la ley formal y material.

El artículo 1 del Código Fiscal de la Federación establece lo siguiente: "Las personas físicas y las morales, están obligadas a contribuir para los gastos públicos conforme a las leyes fiscales respectivas. Las disposiciones de este código se aplicarán en su defecto y sin perjuicio de lo dispuesto por los tratados internacionales de los que México sea parte" [énfasis añadido].

El mismo Código Fiscal prevé así la aplicabilidad de los tratados internacionales como excepción a lo establecido por las leyes fiscales en materia de la obligación general de las personas físicas y morales de contribuir para los gastos públicos. Por lo tanto el límite constitucional del ejercicio de esta facultad, a través de los tratados internacionales que México suscriba, es que no podrán abarcar excepciones generales, y mucho menos particulares, ni establecer tributo alguno que afecten directamente a las personas físicas y morales mexicanas.

Esto se debe a que constitucionalmente la reserva de ley a favor de que los impuestos deban estar establecidos por un acto formal y materialmente legislativo igual al que le dio origen deriva, no del artículo 28 constitucional, sino principalmente del artículo 31 constitucional que establece que, entre las obligaciones de los mexicanos, se encuentra la siguiente: "IV. Contribuir para los gastos públicos, así de la Federación, como del Distrito Federal o del Estado y Municipio en que residan, de la manera proporcional y equitativa que dispongan las leyes".

De esta manera se reserva a la ley la creación de las contribuciones. De conformidad con el artículo 31 y 28 constitucionales, tratándose de

61 Véase Controversia constitucional 32/2002, página 36 y las jurisprudencias ahí señaladas en apoyo a este criterio. 
exenciones de impuestos aplicables a personas físicas o morales mexicanas, éstas deberán siempre contenerse en una ley expedida por el mismo órgano legislativo federal o estatal que estableció el impuesto.

Sin embargo cuando se trata de las facultades de imponer obligaciones de pagar impuestos a los extranjeros y de sus posibles exenciones, éstas derivan no de las obligaciones constitucionales del artículo 31 que se refieren expresamente a los mexicanos, sino de las facultades legislativas impositivas generales de los congresos, ya sea a nivel federal o local. Es así como debe entenderse la disposición del Código Fiscal cuando establece que este regulará las obligaciones de contribuir con los gastos públicos, por parte de las personas físicas y morales, sin perjuicio de lo establecido por los tratados internacionales. Por lo tanto, conforme a lo establecido por el mismo Congreso Federal a través del Código Fiscal, los tratados internacionales tendrán precedencia sobre las leyes fiscales tratándose de las obligaciones de personas físicas y morales extranjeras, incluidos los organismos internacionales con personalidad jurídica.

Las disposiciones de los tratados internacionales que exentan del pago de impuestos a ciertas personas o clases de personas se inscriben dentro de esta interpretación armónica constitucional. Ejemplos lo constituyen como se ha señalado los tratados internacionales en materia de doble tributación, pero también los tratados sobre privilegios e inmunidades de organizaciones internacionales de los cuales México es parte. ${ }^{62}$ Por ejemplo la Convención sobre Prerrogativas e Inmunidades de las Naciones Unidas establece en su sección 7 que las "Naciones Unidas, así como sus bienes, ingresos y otros haberes, estarán exentas de toda contribución directa". ${ }^{63}$ Es por ello también que en este tipo de tratados México se reserva la aplicación de ese privilegio impositivo, entre otros, cuando se trate de funcionarios de Naciones Unidas de nacionalidad mexicana.

En síntesis, la prohibición constitucional a la exención de impuestos contenida en el artículo 28 constitucional no es absoluta. Así lo ha esta-

62 Véase por ejemplo el Acuerdo entre el Gobierno de los Estados Unidos Mexicanos y la Organización de Cooperación y Desarrollo Económicos sobre Privilegios e Inmunidades de la Organización a los Estados Unidos Mexicanos, Diario Oficial de la Federación del 5 de julio de 1994, CT, t. XLVI, p. 11; Acuerdo sobre Privilegios e Inmunidades del Organismo Internacional de Energía Atómica, Diario Oficial de la Federación del 29 de diciembre de 1983, CT, Apéndice I, p. 305, UNTS 5334.

63 Convención sobre Prerrogativas e Inmunidades de las Naciones Unidas, Diario Oficial de la Federación del 10 de mayo de 1963, CT, t. XI, p. 572. 
blecido la Suprema Corte en su jurisprudencia y criterios de interpretación. Conforme a una interpretación armónica de la Constitución, las exenciones de impuestos pueden estar establecidas en un acto formal y materialmente de la misma jerarquía de la ley. En otras palabras, lo que la Constitución prohíbe expresamente es que las exenciones de impuestos se realicen mediante actos de jerarquía inferior a la ley, tales como los actos derivados de la facultad reglamentaria del Ejecutivo federal.

Sin embargo, los tratados internacionales son formal y materialmente de jerarquía superior a las leyes federales y locales. ${ }^{64}$ No obstante lo anterior, un tratado internacional no podría constituir una excepción aplicable a una persona o grupo de personas físicas o morales mexicanas, toda vez que la facultad de establecer los impuestos y exentar de dichos impuestos en el caso particular de los mexicanos está estrictamente reservada a la ley, por disposición del artículo 31 constitucional; es decir, al mismo acto formal y materialmente legislativo que le dio origen.

Basado en lo anterior, un tratado internacional que establece exenciones impositivas para personas o clases de personas extranjeras es perfectamente constitucional toda vez que no violenta el artículo 31 constitucional y la exención deriva de actos de jerarquía igual o superior a la ley. Esta interpretación está confirmada por lo dispuesto en el artículo 1 del Código Fiscal de la Federación, en el que el Congreso federal estableció la aplicación precedente de los tratados internacional en la determinación de las contribuciones a los gastos públicos de personas físicas y morales, a la práctica internacional de la materia por parte de México, y a los límites constitucionales de este ejercicio, descritos anteriormente. Por ello consideramos que ni el artículo 6 del acuerdo marco que se analizó, ni los tratados para evitar la doble tributación, ni los acuerdos con ciertos organismos internacionales, en los que se exime de impuestos al organismo mismo, a su personal o a personas extranjeras, son inconstitucionales y están acorde a la práctica internacional seguida por México en la materia. Por lo anterior, México no necesita imponer restricciones a proyectos como el Banco Europeo de Inversiones y similares, que podrían propiciar financiamiento necesario para grandes inversiones, que difícilmente son accesibles en el contexto nacional. También nos llevan a

64 En particular, es relevante la tesis 192,867 de la Suprema Corte de Justicia que establece: "Tratados internacionales. Se ubican jerárquicamente por encima de las leyes federales y en un segundo plano respecto de la constitución federal", Semanario Judicial de la Federación, México, P. LXXVII/99, tesis 192,867, pleno, 1999, t. 10, p. 46. 
la reflexión sobre políticas fiscales que pueden incentivar la inversión de capitales productivos.

\section{CONCLUSIÓN Y COMENTARIOS FINALES}

En este artículo hemos analizado la situación del régimen de derecho internacional de la inversión extranjera dentro de los procesos de integración económica de México, de la situación de la inversión extranjera en el mundo y en México. Bajo ese contexto analizamos tres instituciones jurídicas que México ha adoptado a través de una diversidad de tratados internacionales que tienen una relación con el clima de la inversión productivas; a saber, el criterio de nivel mínimo de trato a los inversionistas extranjeros bajo el derecho internacional, la disciplina de libre transferencia y convertibilidad y las exenciones impositivas a organismos internacionales financieros con personalidad jurídica.

El nivel mínimo de trato representa desde la óptica que hemos adoptado asumir un compromiso por más debido proceso sustantivo y apego al Estado de derecho. En su relación con los gobernados, las autoridades deben buscar los más altos estándares de calidad en cuanto a servicio público. Esto significa ejercer eficaz y adecuadamente tanto la función de tomador de decisión, de facilitador de resolución de conflictos, como la función de administrador. En el nivel mínimo de trato el énfasis se encuentra también en el proceso. La toma de decisiones debe tomarse con participación de las partes, con oportunidades para ser escuchados, con la mejor información disponible, con adecuada coordinación e intercambio de la misma entre autoridades, y deben de estar no sólo bien fundamentadas en el derecho, sino que los objetivos y herramientas utilizadas deben responder de manera razonada, "justa y equitativamente", a los problemas que se enfrentan y a los objetivos que se plantean.

La disciplina de libre transferencia y convertibilidad constituye un ejemplo de contribución importante al clima de la inversión productiva. Su éxito depende no de la institución legal por sí misma, sino del ejercicio gubernamental adecuado de la política macroeconómica y la generación de confianza social. Esto nos habla de la importancia de que las políticas gubernamentales sean razonables, consistentes y predecibles. Replicar el modelo en el contexto de la relación micro entre autoridades e inversionistas, no sólo en trámites y servicios, sino en el proceso de toma de decisiones administrativas y de gobierno define una segunda ge- 
neración en el desarrollo de una política para la inversión productiva y el buen gobierno. Este es uno de los aspectos que incide en que la mayor parte de la inversión global se dirija y permanezca en los países desarrollados.

Por último, el ejemplo de la exención impositiva a personas morales extranjeras pretende poner de relieve que la Constitución no es impedimento para impulsar proyectos de financiamiento internacional que pueden ser de beneficio para el país. En otro sentido enfatiza la relevancia de los incentivos y esquemas fiscales y financieros para el desarrollo de la inversión productiva nacional e internacional.

La extensión y alcance de este artículo esboza únicamente una primera reflexión sobre las cuestiones planteadas, a reserva de un análisis más profundo y riguroso de los temas abordados. Sin embargo cabe hacer algunos comentarios finales sobre ciertos instrumentos y políticas que se han adoptado recientemente, que se pretenden impulsar o que pudieran desarrollarse en adelante en materia del régimen de la inversión productiva en el país.

Con la adopción de México de mecanismos para la resolución de conflictos en materia de inversión extranjera se lanzaron diversas críticas en el sentido de que estos mecanismos proveían derechos a los inversionistas extranjeros que no existían para los inversionistas nacionales. Si bien es importante resaltar nuevamente que estos mecanismos están basados en el principio de reciprocidad internacional, a partir de las recientes modificaciones al texto constitucional en materia de responsabilidad patrimonial del Estado y en particular de la entrada en vigor de la Ley Federal de Responsabilidad Patrimonial del Estado, el régimen de responsabilidad por la actuación irregular de los órganos de gobierno ha dejado de ser una situación excepcional al régimen de inversión extranjera. Esta nueva política de responsabilidad estatal, aunado al derecho de acceso a la información pública, podrían constituirse en las dos aportaciones más relevantes de los últimos años para incidir en políticas de buen gobierno. El seguimiento y análisis más riguroso de estas políticas y de su instrumentación, así como su extensión al ámbito local, es una de las agendas futuras de la academia nacional, los sectores privados y sociales, así como de los impulsores de reformas a nivel gubernamental nacional y local.

Nos parece que es importante también entender que los conflictos presentan una diversidad de modos de solución. La solución alternativa 
de controversias es un área todavía incipiente como política pública y social en nuestro país. Entendemos poco sobre la anatomía de nuestros conflictos sociales y políticos, los cuales en un porcentaje menor desembocan en conflictos de corte legal-administrativo y jurisdiccional. Todavía no es clara la distinción entre órganos del sector público que pueden coadyuvar a la solución alternativa de conflictos y aquellos que deben actuar como árbitros de lo que no pueda solucionarse en el proceso. De hecho a nivel legal e institucional existen incentivos negativos gubernamentales serios a la solución creativa, justa y equitativa de conflictos. El mismo régimen de responsabilidades de los servidores públicos, en aras de un mal entendido principio de estricta legalidad, se ha constituido como una restricción a la toma de decisiones preventivas o resolutivas más eficaces. Si bien en los últimos años han surgido diversos centros de solución alternativa de conflictos, todavía son marginales y poco aceptados por los mismos órganos jurisdiccionales. Los jueces tienen pocas posibilidades e inclinación a resolver la sustancia de los conflictos o a optar por resoluciones más eficaces y novedosas, sujetos ya sea por una concepción formalista y legalista de su función, o por incentivos y restricciones negativas o falta de incentivos positivos similares a los que enfrentan los servidores públicos bajo el régimen de responsabilidad administrativa y penal gubernamental. Si bien instrumentos legislativos como las leyes de mediación y negociación que han surgido en otras latitudes, o las salidas alternativas en medio jurisdiccional pueden contribuir al desarrollo de este tipo de políticas, el impacto de mayor alcance se encuentra a nivel del sistema nacional de educación jurídica. La capacidad de crear soluciones eficaces y duraderas comienza con la capacidad de pensar crítica y creativamente y de argumentar adecuadamente. Asimismo pasa por el impulso de una ciudadanía más conciente de sus derechos y obligaciones.

Estas reflexiones esbozan algunas consideraciones que de forma directa o indirecta inciden en un sistema de buen gobierno y por lo tanto en la generación de un clima más adecuado para la inversión productiva, independientemente de su origen y monto. Por último consideramos que una política pública en materia de inversión, de la cual requiere México necesariamente, debe dar un paso más allá del registro nacional de inversionistas extranjeros, de las legislaciones específicas en materia de apertura de sectores a la inversión, de una protección más eficaz de los derechos de propiedad intelectual, de la homogenización de normatividad 
con socios comerciales, de las herramientas de control de calidad, tanto sanitaria como de otras normas oficiales particulares, de los organismos de promoción y atracción de grandes capitales, de incentivos fiscales y esquemas financieros adecuados, de desregulación o regulación administrativa adecuada, y de la extensión de acuerdos internacionales de integración económica y de protección a la inversión extranjera y nacional. Todas estas herramientas son necesarias y en mayor o menor grado han contribuido a mejorar el clima de la inversión productiva en el país. Se requiere también seguir avanzando en políticas que incentiven el modelaje de prácticas de buen gobierno a través de iniciativas de coordinación de los sectores públicos, de intercambio de información y comunicación eficaz, de manejo y resolución de conflictos, apegadas a altos estándares de debido proceso y de Estado de derecho, menos legalistas y formalistas, de innovación, con objetivos claros, con estándares de medición sustantiva de resultados, con esquemas de nivelación social y derrama de beneficios económicos, congruentes y consistentes en la medida de la complejidad de la función de gobierno y la realidad social. La reflexión es inicial pero el campo es amplio y retador. Ello con el fin de potenciar lo ya avanzado y mejorar la calidad de vida por lo menos en la extensión de la inversión productiva para el desarrollo.

\section{BIBLIOGRAFÍA}

ASPe ARMElla, Pedro, El camino mexicano de la transformación económica, México, FCE, 1993.

BAER, Werner y BIRCH, Melissa, "Privatization and the Changing Role of the State in Latin America", New York University Journal of International Law and Politics, vol. 25, núm. 1, 1992.

Balasubramanyam, V. N. y GREenWAy, David, "Regional integration agreements and foreign direct investment", en ANDERSON, Kym y BLACKHURST, Richard (eds.), Regional Integration and the Global Trading System, Nueva York-Londres-Toronto, Harvester Wheatsheaf, 1993.

BAZDreSCH, Carlos et al. (eds.), México. Auge, crisis y ajuste, México, FCE, 1992, Lecturas 73.

BlaKeSLEY, Christopher L., The International Legal System: Cases and Materials, 5a. ed., University Casebook Series, 2001. 
Blanco Mendoza, Herminio, Las negociaciones comerciales de México con el mundo, México, Fondo de Cultura Económica, 1994.

CAMERon, Maxwell A. y Tomlin, Brian W., The Making of NAFTA:

How the Deal was Done, Cornell, Cornell University Press. 2000.

CARreau, Dominique, Droit International, 2a. ed., París, Pedone, 1988. y JUILlaRD, Patrick, Droit International Economique, 4a.ed., París, LGDJ, 1998.

Cossío DíAz, José Ramón, Cambio social y cambio jurídico, México, ITAM-Miguel Ángel Porrúa, 2001.

DiCKEN, Meter, Global Shift. Reshaping the Global Economic Map in the 21st Century, 4a. ed., New York, The Guilford Press, 2003.

DUMBERRY, Patrick, The Quest to Define "Fair and Equitable Treatment" for Investors under International Law: The Case of the NAFTA Chapter 11 Pope \& Talbot Awards, The Journal of World Investment, vol. 3, núm. 4, 2002.

GREEN, L.C., International Law through the Cases, 3a. ed., Oceana Publications, 1970.

GreEnberg, Douglas et al. (ed.), Constitutionalism and Democracy. Transitions in the Contemporany World, New York-Oxford, Oxford University Press, 1993.

GrIndLE, Merilee S., Challenging the state. Crisis and innovation in Latin America and Africa, Cambridge, Cambridge University Press, 1996.

FITZMAURICE, "The Law and Procedure of the International Court of Justice", Brit. YBIL, vol. 30, núm. 2, 1953.

Folsom, Ralph H. et al., NAFTA: A Problem-Oriented Coursebook, St. Paul, West Publishers, 2000.

Haggard, Stephan y Kaufman, Robert R., The Political Economy of Democratic Transitions, Princeton, N. J., Princeton University Press, 1995.

HenKIN, Louis et al., International Law, St. Paul,West Publishers, 1987. JACKSON, John, The World Trading System. Law and Policy of International Economic Relations, 2a.ed., Cambridge-London, MIT Press, 1999.

KAPLAN, Marcos, El Estado latinoamericano, México, UNAM, 1996.

KATZ, Isaac, "La inversión extranjera directa de la Unión Europea a México", en LebriJA, Alicia y SBERro, Stephan (eds.), México-Unión Europea. El acuerdo de asociación económica, concertación política 
y cooperación. Sus aspectos fundamentales, México, ITAM-Miguel Ángel Porrúa, 2002.

KHALIL, Mohamed I., "Treatment of Foreing Investment in Bilateral Investment Treaties", Foreing Investment Law Journal, vol. 7, núm. 2, 1992.

LebriJa, Alicia y SBERro, Stephan (eds.), México-Unión Europea. El acuerdo de asociación económica, concertación política y cooperación. Sus aspectos fundamentales, México, ITAM-Miguel Ángel Porrúa, 2002.

LinZ, Juan J. y StePAn, Alfred, Problems of Democratic Transition and Consolidation. Southern Europe, South America, and Post-Comunist Europe, Baltimore-Londres, The John Hopkins University Press, 1996.

LÓPEZ-AYLlón, Sergio, "El impacto del Tratado de Libre Comercio de América del Norte en los sistemas jurídicos del continente americano", en id. (ed.), El futuro del libre comercio en el continente americano. Análisis y perspectivas, México, UNAM, 1997.

—_ Las transformaciones del sistema jurídico y los significados sociales del derecho. La encrucijada entre tradición y modernidad, México, UNAM, 1997.

MANN, F. A., "British Treaties for the Promotion and Protection of Investments", Further Studies in International Law, Oxford Clarendon Press, 1990.

MACCORMICK, John, Understanding the European Union. A Concise Introduction, New York, St. Martin's Press, 1999.

OECD, Foreing Direct Investment for Development. Maximising Benefits, Minimising Costs, París, OCDE, 2002.

OMC, Entender a la OMC, 3a. ed., Ginebra, Organización Mundial del Co- mercio, 2003.

PRZEWORSKI, Adam, Democracia y mercado. Reformas politicas y económicas en la Europa del Este y América Latina, Cambridge, Cambridge University Press, 1995.

Simon, Denys, Le système juridique communautaire, 3a. ed., París, Presses Universitaires de France, 2001.

STIGLITZ, Joseph E., El malestar en la globalización, Madrid, Taurus, 2002.

SZÉKELY, Alberto, Instrumentos fundamentales de derecho internacional público, 2a. ed., México, UNAM, 1989. 
TORRES, Blanca, La adhesión de México al GATT, México, El Colegio de México, 1991.

UNCTAD, Fair and Equitable Treatment, UNCTAD Serier on issues on international investment agreements, vol. 3 (UNCTAD/ITE/IIT/ 11(vol.III)).

VALDEZ ABASCAL, Rubén y ROMERO APIS, José Elías (eds.), La modernización del derecho mexicano, México, Porrúa, 1994.

Vega CÁnovas, Gustavo, "México en las nuevas tendencias de la economía y el comercio internacionales", Foro Internacional, vol. XXVIII, núm. 1, 1987.

et al., México, Estados Unidos y Canadá: Resolución de controversias en la era post Tratado de Libre Comercio de América del Norte, IIJ-PIERAN-El Colegio de México, 2005.

WOBESER, Claus von, "El régimen legal de la inversión extranjera en el TLCAN y sus efectos en los flujos de capital hacia México", en LEYCEGUi, Beatriz y FERnÁNDEZ DE CASTRO, Rafael (eds.), ¿Socios naturales? Cinco años del Tratado de Libre Comercio de América del Norte, México, ITAM-Miguel Ángel Porrúa, 2000.

WITKER, Jorge y HERNÁNDEZ, Laura, Régimen jurídico del comercio exterior en México, México, UNAM, 2000. 